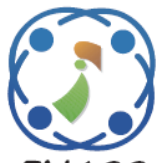

\title{
Integrated Controller for Elimination of Harmonics in PMSG Based WECS Feeding Non Linear Load
}

\author{
Sujith Mayakrishnan ${ }^{1 *}$, Padma Srinivasan ${ }^{2}$, Ashokkumar Loganathan ${ }^{3}$ \\ ${ }^{1}$ IFET College of Engineering, Villupuram, Tamilnadu, India \\ ${ }^{2}$ Sona College of Technology, Salem, Tamilnadu, India \\ ${ }^{3}$ PSG College of Technology, Coimbatore, Tamilnadu, India \\ * Corresponding author's Email: msujitheee@yahoo.co.in
}

\begin{abstract}
This paper presents a simple and robust fuzzy logic with Adaptive linear Neuron (Adaline) controller. It is used for controlling the Direct driven Permanent Magnet Synchronous Generator (D-PMSG) based Wind Energy Conversion System(WECS) supplying three phase loads. In practice the loads are non-linear in nature and therefore harmonics are injected in to the generating system. By this PMSG is affected by these harmonics and leads to poor voltage regulation and requires adjustable reactive power source. The fuzzy logic is employed as control strategy for machine side converter to maintain the constant DC voltage supplying to GSC without any additional DC-DC converter. The Adaline Based Load Side Converter (LSC) is employed to mitigate the harmonics and delivering the reactive power co-ordinately to load. A dynamic model of PMSG feeding Linear / Non linear loads using synchronous reference frame method are developed for predicting the system behaviour under various loading conditions. The result shows that the wind turbine operates at variable speed with optimized performance and the power quality improvement can be achieved in terms of minimum total harmonic distortion (THD) according to the IEEE 519 standard. The Adaline controller is used for accurate estimation of phase and frequency at the point of common coupling (PCC). The feasibility of the proposed system model and integrated control strategy are verified using MATLAB/Simulink simulations.
\end{abstract}

Keywords: Adaptive linear neuron, Fuzzy logic control, Load side converter, Machine side converter, Total harmonics distortion, Permanent magnet synchronous generator, Synchronous reference frame.

\section{Introduction}

Wind Energy is the most important renewable energy source used for power generation for independent operation as well as grid connected applications. In recent years the usage of wind energy is increased significantly, because of clean and free utilized to meet the energy demand in Power Sector Corporation. The isolated power generations are supported by various national environmental policies [1-3]. Permanent Magnet Synchronous Generator (PMSG) has more significant advantages of wind turbine efficiency whereas variable speed operations are achieved in different applications. The main problem associated with PMSG is to control the voltage and frequency in various loading capacity
[4,5]. The gird side reactive power compensation and filtering of non linear load harmonics are controlled by Machine Side converter [6]. In this contribution, the GSC is used as shunt active filter in order to achieve the reactive power compensation. The effectiveness of harmonic compensation at front end rectifier is discussed by connecting the inverter to the DC link of the active rectifier in order to minimize the ripples [7]. The STATCOM is employed to control the voltage, harmonic elimination, $\mathrm{PF}$ improvement, reactive power compensation under various load condition. In addition to that, harmonics injected by load are suppressed and reactive power compensation is achieved [8-9]. In this proposed work, Adaline controllers are used to estimate the harmonic currents generated by non-linear loads and cancelled the harmonic currents by controlling the 
pulse given to the Voltage source converter (VSC). The fuzzy Interference system is used to achieve fast dynamic response, no overshoot and reduction of settling time is achieved to maintain the constant DC voltage [10]. In [11] studied the injection of negative sequence current for reducing the unbalanced voltage at the point of PCC. The rotor currents are decoupled in to direct component and quadrature component for regulating active and reactive power using PI Controllers [12-13]. In [14], studied the contribution of SVC with Artificial Neuro- Fuzzy Interference system (ANFIS) is used to overcome the disturbance occurred during various operating conditions. The fuzzy based PI controller is established in PMSG to improve the dynamic response and minimize the ripple in DC link connected between converters. In this contribution of work, integrated Fuzzy model is used to control the machine side converter to provide the constant DC link voltage without additional boost converter. The Adaline controller is used to provide the reactive power compensation during various loading condition and mitigate the harmonics by estimating the harmonic currents. According to IEEE 519-1992 \& IEC 61000-3-2/IEC 61000-3-4 Europe Standard, current and voltage harmonics restrictions are maintained in many countries associated with power generation from clean energy.

The novel features of this proposed work are to 1 . Analyze the impact of harmonics injected at the point of common coupling due to non linear loads 2.The proposed controller will achieved the minimum THD Value of $3.87 \%$ compared to non conventional controller 3.Compensate the reactive power 4. Able to maintain the constant DC link voltage at variable wind speed with the help of fuzzy based PI Controller. Harmonics are injected at the generating systems due to the continuous drawing of non sinusoidal currents which results in distortion of terminal voltage. The reference currents are estimated by the different control algorithms, in this case Adaline controller are used because of simplicity and stability under various loads.

The mathematical model, topology of the proposed system and results are discussed in this paper. In section 1 deal with system configuration and principle of operation. The mathematical model for the rotor side controllers are proposed in section 2. In section 3 elaborates the fuzzy logic control strategies used to maintain DC link voltage. In Section 4 describes the mathematical derivatives and control algorithm for load side controller (LSC). The Matlab simulation results for proposed control strategies are discussed in section 5 .

\section{System configuration and principle of operation}

A typical PMSG system is connected through load is full scale back to back converter as shown in figure.1. A three phase linear/non linear load is connected to the direct driven PMSG through back to back VSC converter. The fuzzy logic controllers are employed to estimate the dc voltage and calculate the current components of PMSG for maintaining the DC link voltage for supplying constant voltage to Load side converter. Moreover the loads are nonlinear in nature, adaline controllers are used to compare the reference source currents with estimated harmonic currents generated by the loads and then the error signal is given to controller for generating the pulses to control the load side converter. The Inphase and quadrature phase templates of the load side is calculated for estimation of reference source currents.

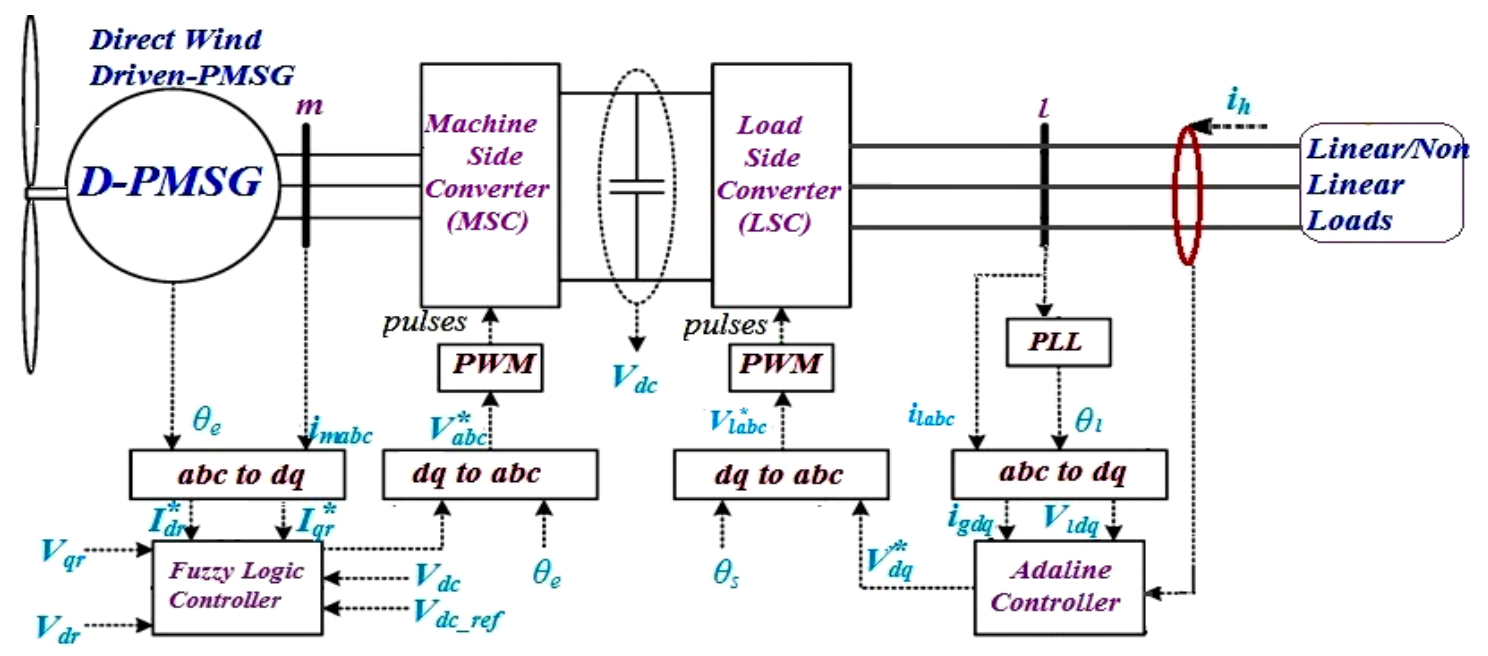

Figure.1 Proposed study model of D-PMSG feeding non-linear loads 


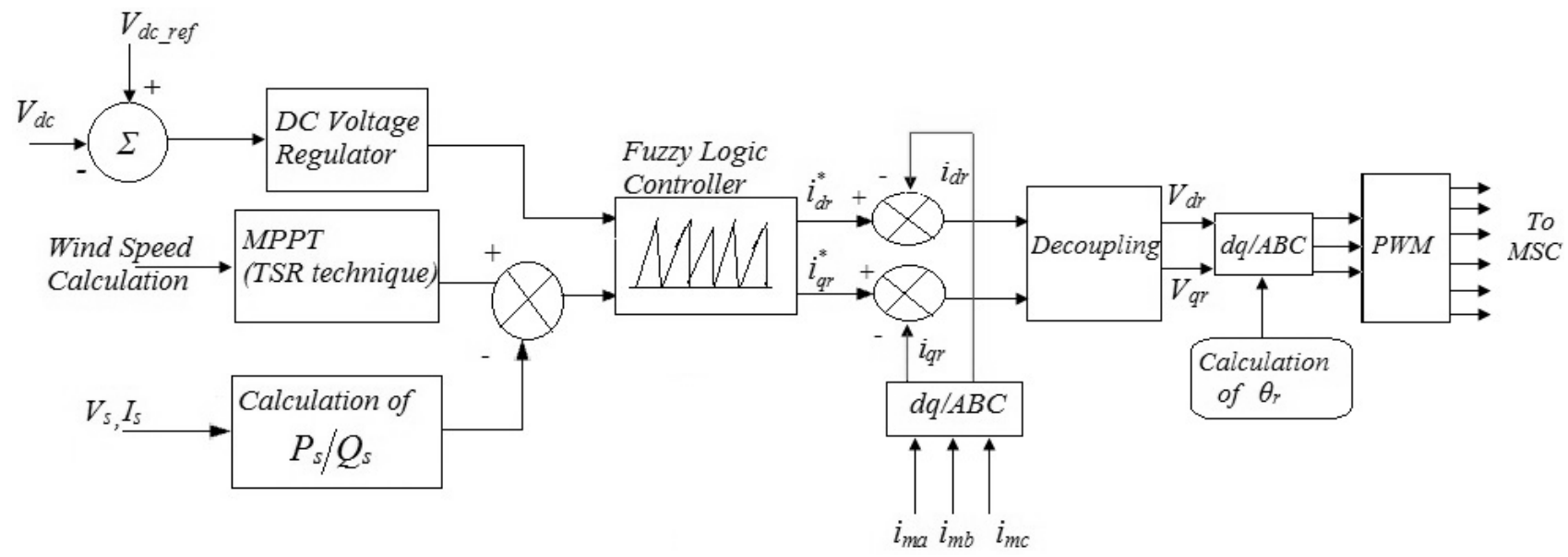

Figure.2 MSC Control scheme using FLC

The proposed control strategies are divided into six sections. First section deals with the Control scheme of MSC. Second Section deals with mathematical modeling of $\mathrm{ABC} / \mathrm{DQ}$ reference frame for MSC. Third Section deals with mathematical modeling of $\mathrm{DQ} / \mathrm{ABC}$ reference frame for GSC.

Fourth section is described in detail about the design of fuzzy logic variables for MSC side. Fifth section is discussed about the control strategy of Adaline controllers used for Linear / Non linear loads to mitigate the Harmonics. Sixth section deals with proposed system simulation results and discussion using MATLAB/Simulink.

\section{Control algorithm of machine side converter (MSC)}

The machine side converter is used to decoupling the active and reactive power by using the synchronous reference frame theory. FLC is employed to provide the reactive power control in the load. The main objective of MSC is to extract the real power and to control the reactive power.

The control structure involves two loops, the inner loop function is to regulate the dq components i.e. $\mathrm{I}_{\mathrm{dr}}$ and Iqr independently and outer loop function is to regulate the stator real power and reactive power independently (Fig.2).

The power reference signal is used to calculate the error signal. The error signal values and derivatives are given as inputs of fuzzy interference systems. The fuzzy controller is used to set reference value zero for reactive power. Tip-speed ratio technique is employed in MPPT controller to track the maximum speed of the PMSG.In this proposed method, the speed of the wind is considered to be constant. For regulating the dc voltage, the rotor currents of d-axis and q-axis components are used. The q-axis is assigned to zero $\left(\psi_{q s}=0\right)$ for decoupled control of real and reactive power. The controller outputs are derived by the below equations

$$
\frac{d \psi_{q s}}{d t}+\frac{R_{s}}{\sigma L_{s}} \psi_{q s}=-w_{e} \psi_{d c}+\frac{R_{s} L_{m}}{\sigma L_{s} L_{r}} \psi_{q r}+V_{q s}
$$

The stator flux calculation is given by

$$
\begin{aligned}
& \sigma_{\psi_{q s}}=-w_{e} \psi_{d c}+\frac{R_{s} L_{m}}{\sigma L_{s} L_{r}} \psi_{q r}+V_{q s} \\
& \left.\psi_{d s}^{*}=\frac{1}{w_{e}}\left(\frac{R_{s} L_{m}}{\sigma_{L S} L_{r}} \psi_{d c}+V_{q s}-\sigma_{\psi q s}\right)\right\} \\
& d \psi_{d s}+\frac{R_{s}}{\sigma L_{s}}=\frac{1}{w_{e}}\left(\frac{R_{s} L_{m}}{\sigma_{L S} L_{r}} \psi_{d c}+V_{d s}-\sigma_{\psi d s}\right)
\end{aligned}
$$

Where

$$
\sigma_{\psi d s}=\frac{d \psi_{q s}}{d t}+\frac{R_{s}}{\sigma L_{s}} \psi_{s}=K_{p} \psi_{s}+\frac{K_{I \psi s}}{P}\left(\psi_{q s}^{*}-\psi_{q s}\right)
$$

From (2) and (3)

$$
\sigma_{\psi d s}=P \psi_{q s}+\frac{R_{s}}{\sigma L_{s}} \psi_{s}=K_{p} \psi_{s}+\frac{K_{I \psi s}}{P}\left(\psi_{q s}^{*}-\psi_{q s}\right)
$$

From above derivatives $\sigma_{\psi \mathrm{qs}}$ and $\sigma_{\psi \mathrm{ds}}$ are terms used to determine the output of controller.

The stator active power is derived by the following equation 


$$
P_{s}=\frac{3}{2}\left(V_{q s} I_{q s}+V_{d s} I_{d s}\right)=-\frac{3}{2} \frac{L_{m}}{L_{s}} V_{q s} I_{q r}
$$

The stator supplied reactive power is derived as

$$
Q_{s}=\frac{3}{2}\left(V_{q s} I_{q s}+V_{d s} I_{d s}\right)=\frac{3}{2} \frac{L_{m}}{L_{s}} V_{q s} I_{q r}
$$

Differentiate with respect to time

$$
\frac{d Q_{s}}{d t}=-\frac{3}{2} \frac{w_{e}}{\sigma_{L S}} \cdot \frac{L_{m}}{L_{r}} \psi_{d s} \cdot \frac{d \psi_{d r}}{d t}
$$

By solving (7) \& (8) in terms of $I_{d r}$ gives

$$
\frac{d Q_{s}}{d t}=-\frac{3}{2} \frac{W_{e}}{\sigma L_{s}} \cdot \frac{L_{m}}{L_{r}} \psi_{d s}\left(\begin{array}{l}
V_{d r}-R_{r} I_{d r}+ \\
\left(w_{e}-w_{r}\right) \psi_{d r}
\end{array}\right)
$$

Where

$$
\nabla=\frac{2 \sigma L_{s} L_{r}}{3 w_{e} L_{m}}
$$

and Kqs is stator side controller. From Eqs.(8) and (9)

$$
I_{d r}^{*}=\frac{1}{R_{r}}\left(V_{d r}+\left(w_{e}-w_{r}\right) \sigma L_{r} L_{q r}+\frac{\sigma Q_{s}}{\psi_{d s}}\right.
$$

From Eqs. (8) and (9), $\mathrm{P}_{\mathrm{s}}$ and $\mathrm{Q}_{\mathrm{s}}$ are proportional to $\mathrm{I}_{\mathrm{qr}}$ and $\mathrm{I}_{\mathrm{dr}}$. The rotor voltages are regulated by means of rotor currents. Relation between Rotor voltage and current is obtained by

$$
\begin{aligned}
& V_{q r}=R_{r} I_{q r}+\sigma L_{r} P I_{d r}+w_{s l}\left[\frac{L_{m}}{L_{s}} \psi_{d s}+\sigma L_{r} I_{d r}\right] \\
& V_{d r}=R_{r} I_{d r}+\sigma L_{r} P I_{d r}-w_{s l} \sigma L_{r} P I_{q r}
\end{aligned}
$$

From above Eqs. (11) and (12), $\mathrm{I}_{\mathrm{dr}}$ and $\mathrm{I}_{\mathrm{qr}}$ equations are coupled and linearized by FLC controller (Fig.3).

$$
\begin{gathered}
\sigma_{q r}=R_{r} I_{q r}+\sigma L_{r} P I_{q r} \\
\sigma_{d r}=R_{r} I_{d r}+\sigma L_{r} P I_{d r}
\end{gathered}
$$

The Fuzzy Controllers are used to integrate the derivative to q-axis and d-axis voltage

$$
\begin{aligned}
& V_{q r}=\sigma_{d r}+w_{s l}\left(\frac{L_{m}}{L_{s}} \psi_{d s}+\sigma L_{r} I_{d r}\right) \\
& V_{d r}=\sigma_{d r}+w_{s l}\left(\sigma L_{r} I_{q r}\right)
\end{aligned}
$$

\section{Fuzzy logic controller}

FLC is useful for designing the rules of non linearity systems such as wind turbine systems. FLC rules (Fig.3) are similar to human decisions and it contains similar knowledge of the system. In this proposed model, FLC based control strategies are used to control and maintain the constant DC link voltage.

In proposed system, seven sets of fuzzy logic have been considered: NB , NM, NS, ZE, PS,PM,PB. The structure of membership function shown in figure 4 .

The design part consists into (i) determine the no of inputs (ii) allocation of rules (iii) designed a logic to convert fuzzy variables into output signals. The proposed logic based on DC link voltage variation from the reference signal $\mathrm{V}_{\mathrm{dcref}}$ and the variation $\Delta \mathrm{V}_{\mathrm{dc}}$ during sampled period is given by

$$
\Delta V_{d c}=V_{d c}-V_{d c r e f}
$$

Sampled Period is given below

$$
\delta\left(\Delta V_{d c}\right)=\Delta V_{d c}(n)-\Delta V_{d c}(n-1)
$$

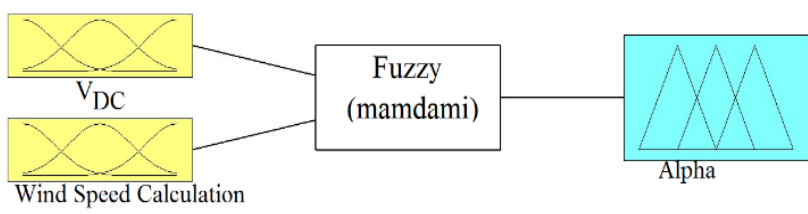

Figure 3. Membership function of Fuzzy logic controller

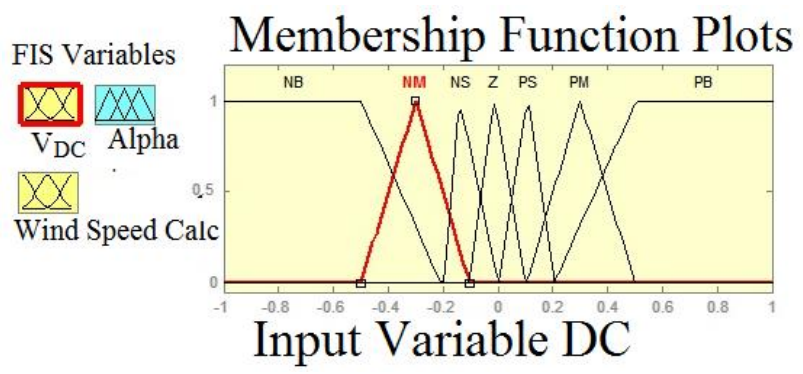

Figure 4. Membership function of Fuzzy logic controller 
Table 1. Rules for fuzzy logic controller

\begin{tabular}{|c|c|c|c|c|c|c|c|}
\hline \multirow{2}{*}{$\delta\left(\Delta \mathrm{V}_{d c}\right)$} & \multicolumn{7}{|c|}{$-\Delta \mathrm{V}_{d c}$} \\
\cline { 2 - 8 } & $\mathbf{N B}$ & NM & NS & $\mathbf{Z E}$ & PS & PM & PB \\
\hline NB & NB & NB & NM & NM & NS & NS & ZE \\
\hline NM & NB & NM & NM & NS & NS & ZE & PS \\
\hline NS & NM & NM & NS & NS & ZE & PS & PS \\
\hline ZE & NM & NS & NS & ZE & PS & PS & PM \\
\hline PS & NS & NS & ZE & PS & PS & PM & PM \\
\hline PM & NS & ZE & PS & PS & PM & PM & PB \\
\hline PB & ZE & PS & PS & PM & PM & PB & PB \\
\hline
\end{tabular}

The deviation $e=V_{d c r e f}-V_{d c}$ and the rate of deviations are $\mathrm{V}_{\mathrm{dc}}$. The inputs are continuously calculated and checked by the FLC and the controllers are subjected to change in deviation is obtained in order to achieve optimal parameters. FLC is used to tuning the appropriate values of variables by using above rules (Fig. 5).

The corresponding fuzzy set variables are

$$
e, e_{c}, \Delta P, \Delta Q=\{N B, N M, N S, Z E, P S, P M, P B\}
$$

The designed output variables are converted into output signals of desired quantity. The centroid defuzzification method is used to extract the accurate output. The membership functions are achieved by the centre of area under the curve. It can be expressed as

$$
Z_{o}=\frac{\int \mu_{i}(x) x d x}{\mu_{i}(x) d x}
$$

Consider $\mu_{i}=\Delta V_{d c}, x=\Delta V_{d c r e f}$

Where $Z_{0}=$ Defuzzified output, $\mu_{i}=$ membership function, $x=$ output variable

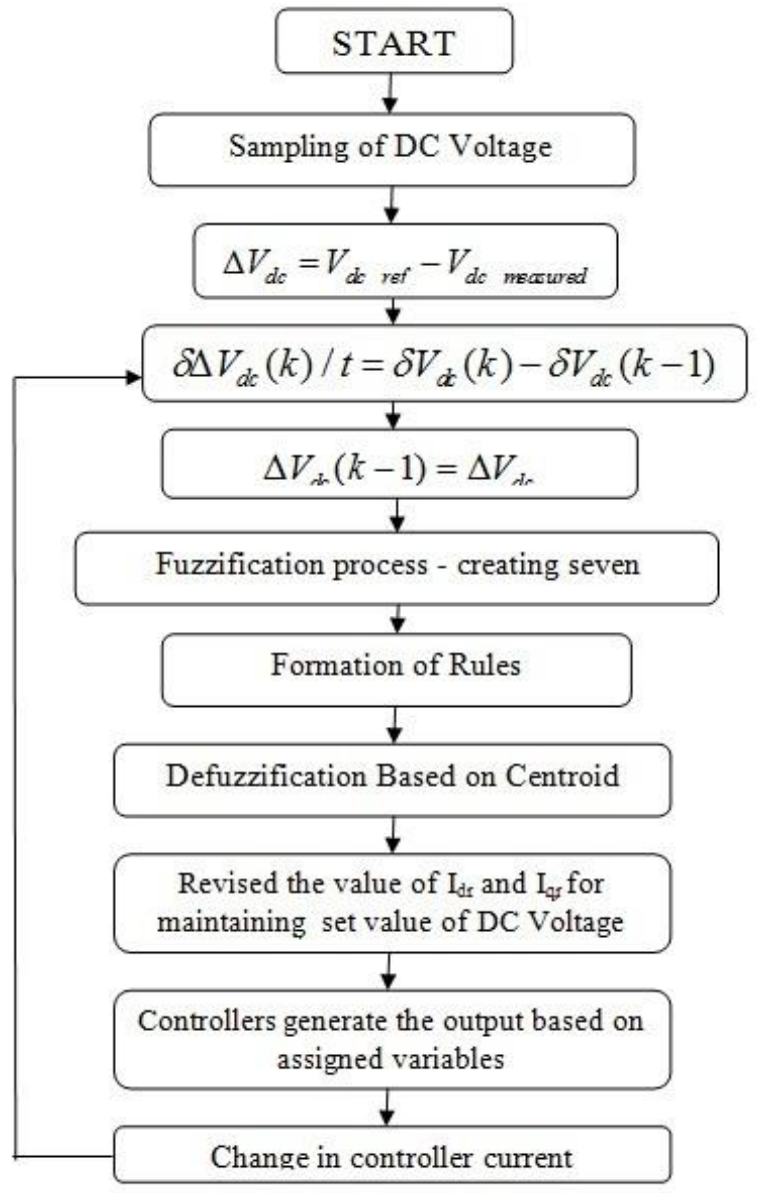

Figure 5. Flowchart for DC Voltage regulation using Fuzzy Rule

\section{Control algorithm for load side converter (LSC)}

The control algorithm used for load side converter is Adaline controller used to extract the phase templates (In phase \& Quadrature), estimate the active and reactive power components of reference currents [14]. The control scheme is shown in Fig.6.

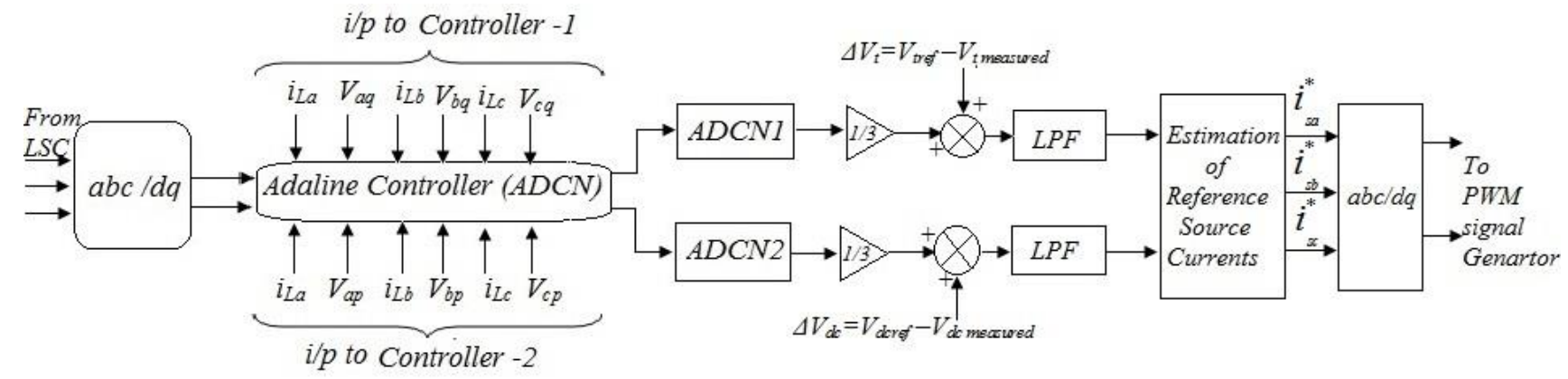

Figure 6. Adaline controller for LSC 
The instantaneous values of currents can be obtained and written as following.

$$
\left.\begin{array}{c}
L_{i} \frac{d i_{a l}}{d t}=V_{a}-R_{l} i_{a l}-V_{(a, 0)} \\
L_{i} \frac{d i_{b l}}{d t}=V_{b}-R_{l} i_{b l}-V_{(b, 0)} \\
L_{i} \frac{d i_{c l}}{d t}=V_{c}-R_{l} i_{c l}-V_{(c, 0)}
\end{array}\right\}
$$

Considering the $\mathrm{V}_{(\mathrm{a}, 0)}, \mathrm{V}_{(\mathrm{b}, 0)}, \mathrm{V}_{(\mathrm{c}, 0)}$ are voltage from ac side from neutral point 0 ,

$$
\left.\begin{array}{c}
V_{(a, 0)}=V_{(a, N)}+V_{(N, 0)} \\
V_{(b, 0)}=V_{(b, N)}+V_{(N, 0)} \\
V_{(c, 0)}=V_{(c, N)}+V_{(N, 0)}
\end{array}\right\}
$$

Considering only balanced three phase system

$$
V_{(a, 0)}+V_{(b, 0)}+V_{(c, 0)}=0
$$

From Eqs.(22) and (23),

$$
V_{(N, 0)}=\frac{V_{(a, N)}+V_{(b, N)}+V_{(c, N)}}{3}
$$

Considering phase A

$$
\begin{aligned}
\mathrm{S}_{\mathrm{a}}=1 & =\text { Upper Switch=ON, Lower } \text { Switch=OFF } \\
& =>\mathrm{V}_{(\mathrm{a}, \mathrm{N})}=\mathrm{V}_{\mathrm{dc}} \\
\mathrm{S}_{\mathrm{a}}=0 & =\text { Upper Switch=OFF, Lower Switch=ON } \\
& =>\mathrm{V}_{(\mathrm{a}, \mathrm{N})}=0
\end{aligned}
$$

From Above characteristics $\mathrm{V}_{(\mathrm{a}, \mathrm{N})}=\mathrm{S}_{\mathrm{a}} \cdot \mathrm{V}_{\mathrm{dc}}$ Similarly therefore

$$
\left.\begin{array}{l}
V_{(a, N)}=S_{a} \cdot V_{d c} \\
V_{(b, N)}=S_{b} \cdot V_{d c} \\
V_{(c, N)}=S_{c} \cdot V_{d c} \\
V_{(N, 0)}=-\frac{1}{3}\left(S_{a}+S_{b}+S_{c}\right) V_{d c}
\end{array}\right\}
$$

Substituting Eqs.(22) and (25) in (21),

$$
\left.\begin{array}{l}
L_{i} \frac{d i_{a l}}{d t}=V_{a}-R_{l} i_{a l}-V_{d c}\left(S_{a}-\frac{1}{3} \Sigma S_{k}\right) \\
L_{i} \frac{d i_{b l}}{d t}=V_{b}-R_{l} i_{b l}-V_{d c}\left(S_{a}-\frac{1}{3} \Sigma S_{k}\right) \\
L_{i} \frac{d i_{c l}}{d t}=V_{c}-R_{l} i_{c l}-V_{d c}\left(S_{a}-\frac{1}{3} \Sigma S_{k}\right)
\end{array}\right\}
$$

The extraction of quadrature phase and In-phase components are expressed as

$$
\left[\begin{array}{l}
V_{s a} \\
V_{s b} \\
V_{s c}
\end{array}\right]=\frac{1}{3}\left[\begin{array}{cc}
2 & 1 \\
-1 & 1 \\
-1 & -2
\end{array}\right]\left[\begin{array}{l}
V_{s a b} \\
V_{s b c}
\end{array}\right]
$$

where as

$$
u_{a p}=\frac{V_{s a}}{V_{t}}, u_{b p}=\frac{V_{s b}}{V_{t}}, u_{c p}=\frac{V_{s c}}{V_{t}}
$$

The above Equations is called as Inphase Templates $\mathrm{V}_{\mathrm{sa}}, \mathrm{V}_{\mathrm{sb}}, \mathrm{V}_{\mathrm{sc}}$ are the instantaneous phase voltages. The Quadrature templates are extracted using in-phase templates

$$
\left.\begin{array}{l}
u_{a p}=\frac{\left(-u_{b p}+u_{c p}\right)}{\sqrt{3}} \\
u_{b q}=\frac{\left(3 u_{a p}+u_{b p}-u_{c p}\right)}{\sqrt{3}} \\
u_{c q}=\frac{\left(-3 u_{a p}-u_{b p}+u_{c p}\right)}{\sqrt{3}}
\end{array}\right\}
$$

The active power components are estimated by using weight vector is given as

$$
w_{p}(n)=\left(\begin{array}{l}
w_{p}(n-1)+\mu^{*}(n-1)+ \\
\mu^{*}\left(i_{L}(n)-\left(w_{p}(n)^{*} u_{p}(n)\right)^{*} \cdot u_{p}(n)\right.
\end{array}\right)
$$

where $\mu$ is a fixed step size.

The instantaneous active vector components are derived by multiplying weight vectors as follows

$$
\left.\begin{array}{l}
i_{s a p}(n)=w_{P T}(n)^{*} \cdot u_{a p}(n) \\
i_{s b p}(n)=w_{P T}(n)^{*} \cdot u_{b p}(n) \\
i_{s c p}(n)=w_{P T}(n)^{*} \cdot u_{c p}(n)
\end{array}\right\}
$$


The reactive power components of reference source current estimated as follows

$$
w_{q}(n)=\left(\begin{array}{l}
w_{q}(n-1)+\mu^{*}(n-1)+ \\
\mu^{*}\left(i_{L}(n)-\left(w_{q}(n)^{*} u_{q}(n)\right)^{*} \cdot u_{q}(n)\right.
\end{array}\right)
$$

where $\mu$ is a fixed step size.

The instantaneous reactive vector components are derived by multiplying weight vectors as follows

$$
\left.\begin{array}{l}
i_{s a q}(n)=w_{P T}(n)^{*} \cdot u_{a q}(n) \\
i_{s b q}(n)=w_{P T}(n)^{*} \cdot u_{b q}(n) \\
i_{s c q}(n)=w_{P T}(n)^{*} \cdot u_{c q}(n)
\end{array}\right\}
$$

The instantaneous reference source current obtained from Eqs. (31) and (33).

$$
\begin{aligned}
& i_{s a}^{*}=i_{s a p}^{*}+i_{s a q}^{*} \\
& i_{s b}^{*}=i_{s b p}^{*}+i_{s b q}^{*} \\
& i_{s c}^{*}=i_{s c p}^{*}+i_{s c q}^{*}
\end{aligned}
$$

\section{Simulation results and discussion}

The Simulation of the proposed systems using fuzzy and Adaline controllers are evaluated using Matlab/Simulink for different wind profile (fixed and variable speed mode) shown in Fig. 7.

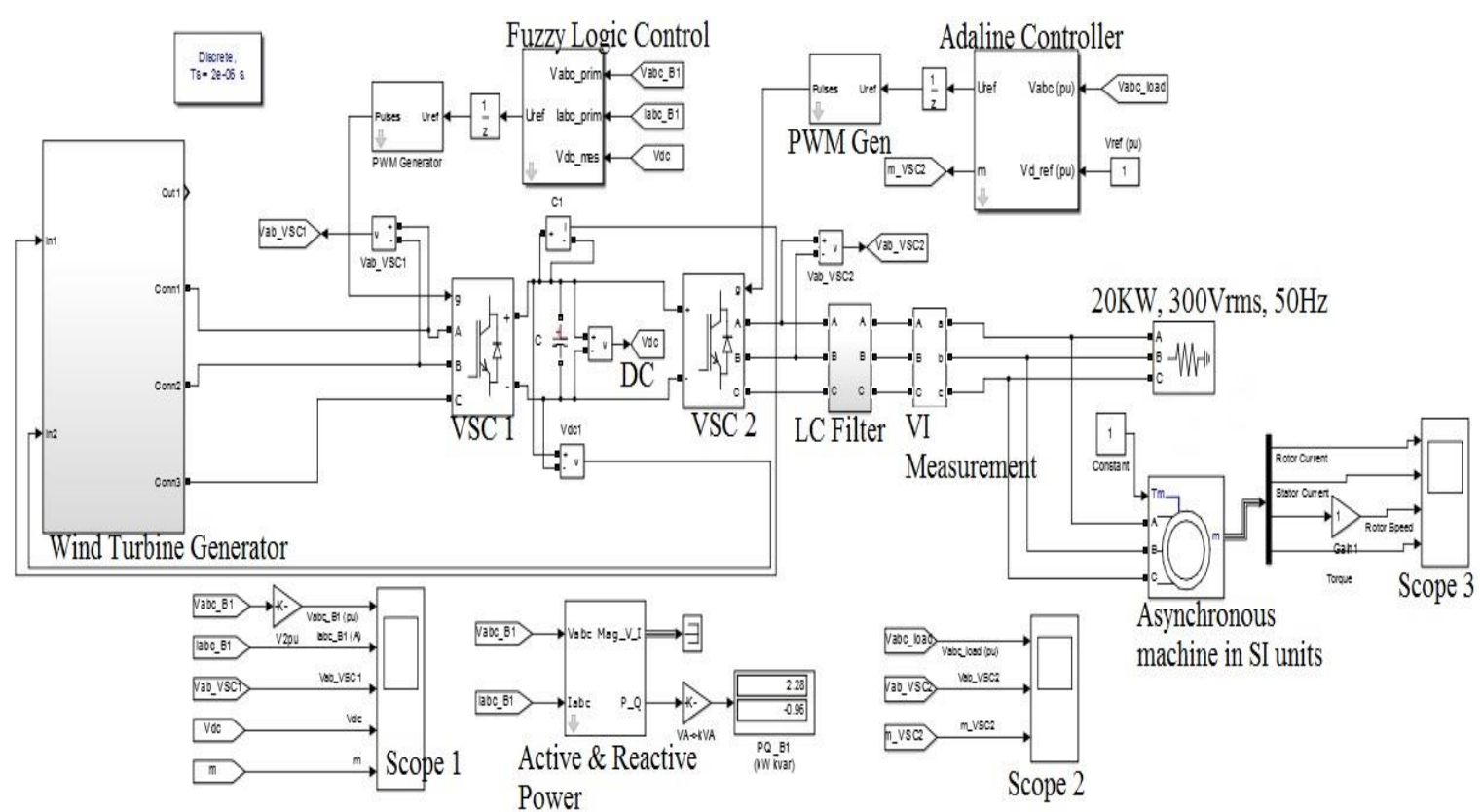

Figure 7.Proposed PMSG-WECS Matlab/Simulink Model

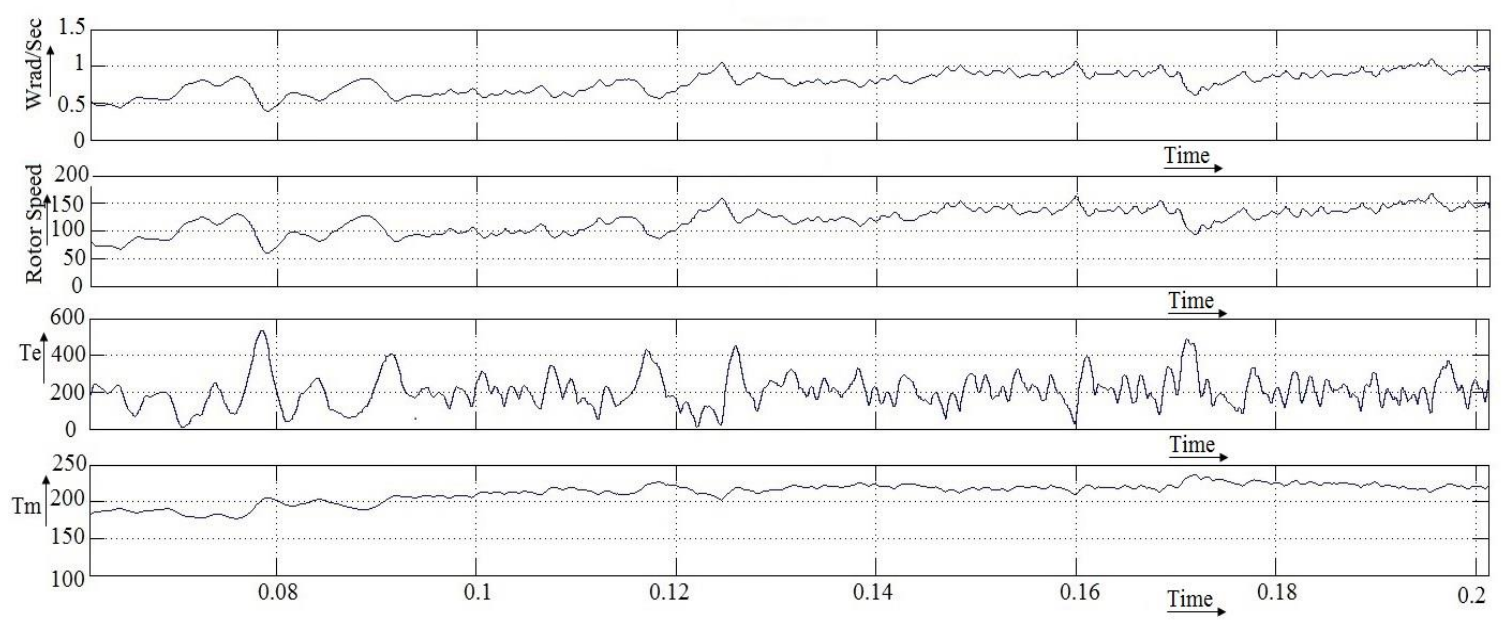

Figure 8. Characteristics of PMSG -WECS 


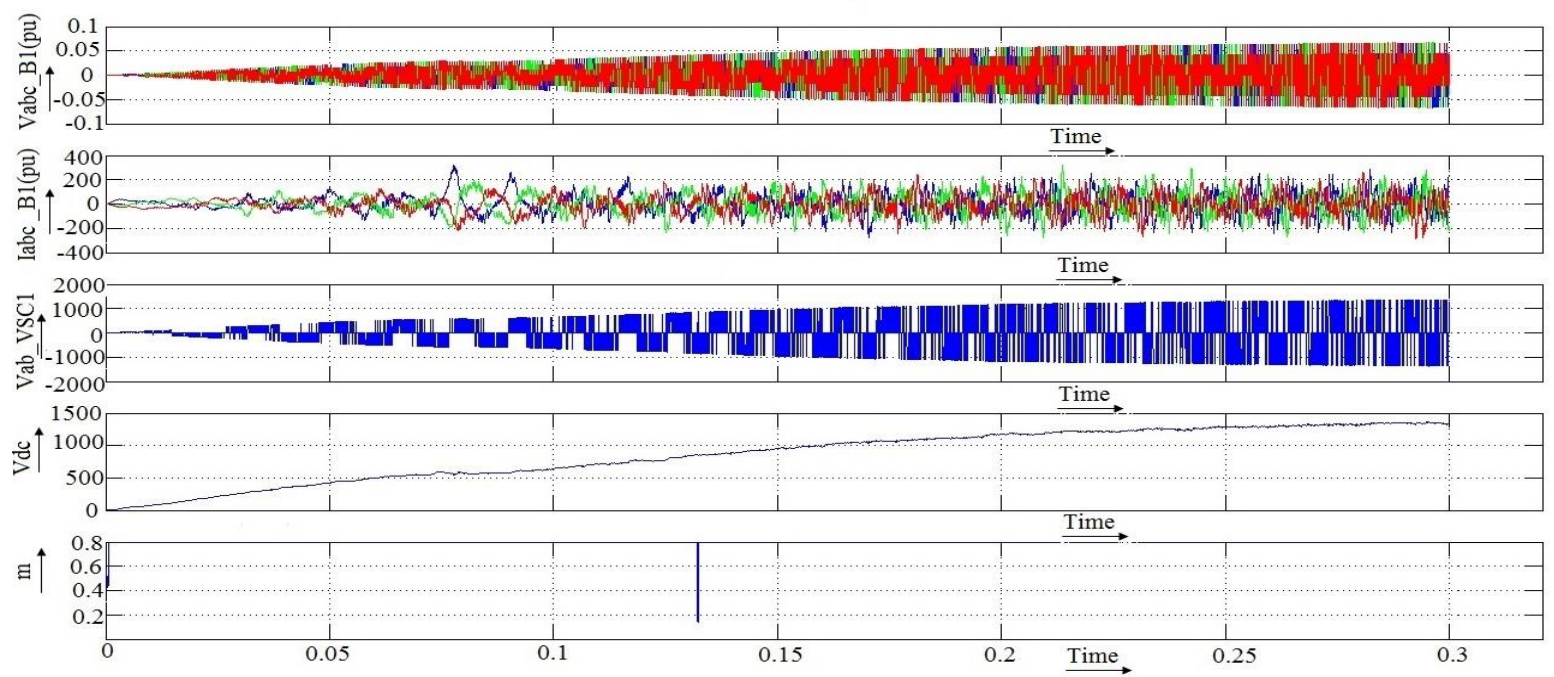

Figure 9. Output of Machine Side Converter (VSC1) and DC link voltage
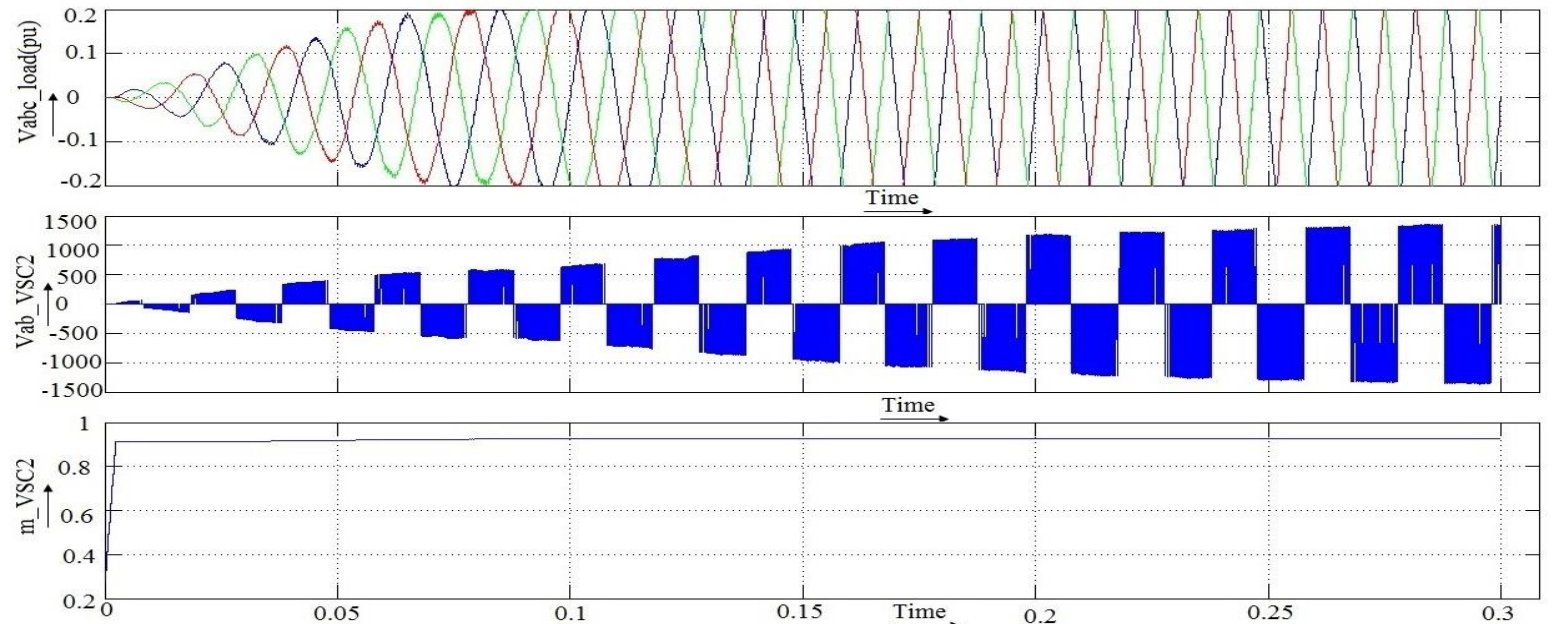

Figure 10. Output of Load Side Converter (VSC2)
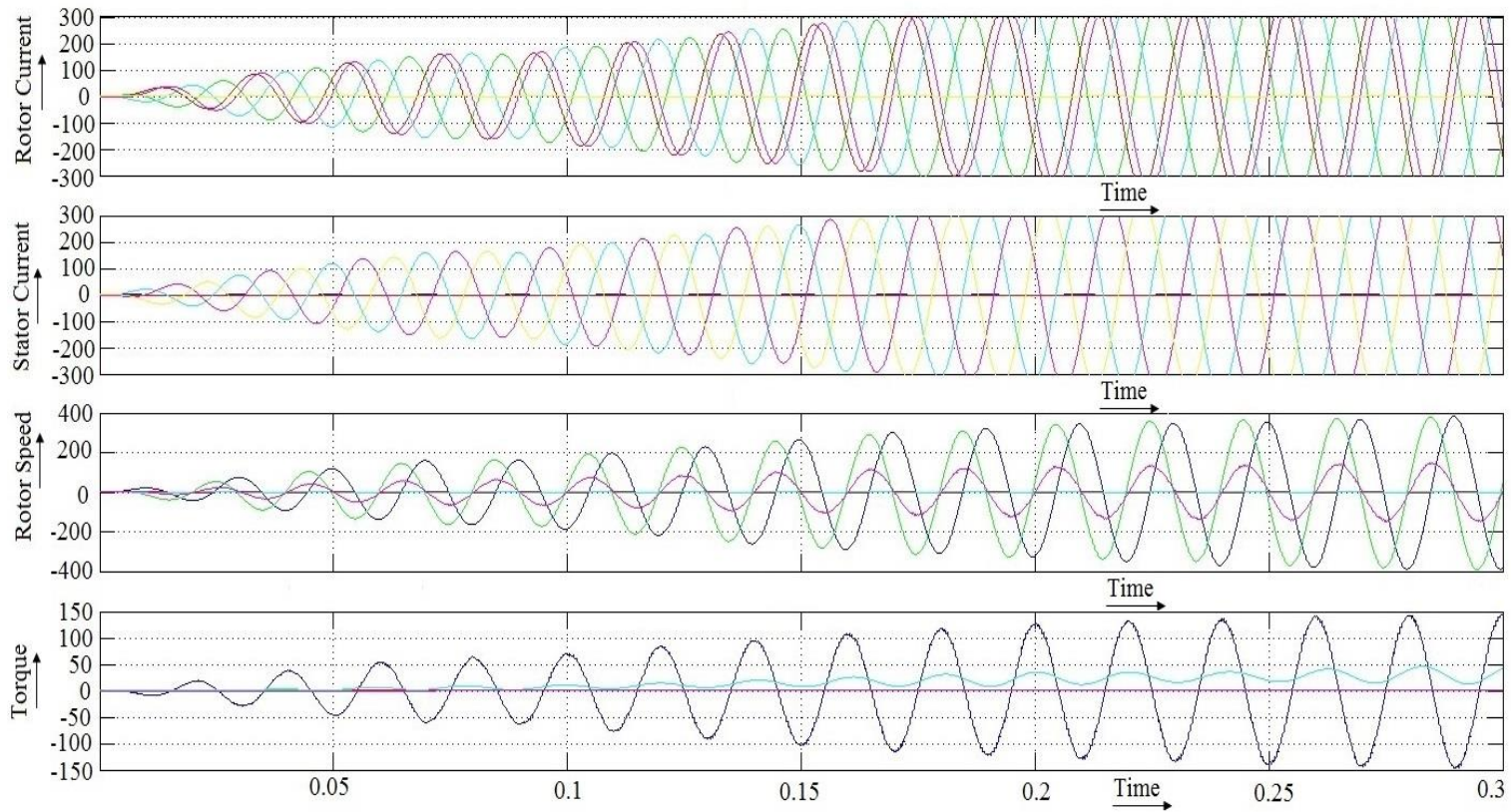

Figure 11. Output of the Load 2 (Squirrel Cage IM connected through VSC2) 
Table 3. Percent THD of various loads

\begin{tabular}{|c|c|c|}
\hline $\begin{array}{c}\text { Type of } \\
\text { Load }\end{array}$ & $\begin{array}{c}\text { THD } \\
\text { (Proposed) }\end{array}$ & $\begin{array}{c}\text { THD } \\
\text { (Conventional) }\end{array}$ \\
\hline RL Load & $0.07 \%$ & $2.03 \%$ \\
\hline $\begin{array}{c}\text { Squirrel } \\
\text { Cage IM }\end{array}$ & $3.87 \%$ & $7.03 \%$ \\
\hline
\end{tabular}

The proposed system model is implemented using Matlab/Simulink with Fuzzy and Adaline converters are depicted in Fig. 7. Figures 8 illustrates the different wind profile $\mathrm{w}(\mathrm{rad} / \mathrm{s})$, rotor speed $\omega_{\mathrm{m}}$ $(\mathrm{rad} / \mathrm{sec})$, characteristics of electrical and mechanical torque of PMSG Turbine.

PMSG-WECS Simulated in following conditions:

- Rotor flux position when theta $=0$ ( 90 degrees behind A phase)

- Wind Speed Set up to $12 \mathrm{~m} / \mathrm{sec}$ (Simulated in both fixed and variable mode

Figures from 9 to 10 illustrates the output of voltage source converter 1 (MSC), DC Voltage, modulation index value and the output of voltage source converter 2 (LSC). Figures 11 depicts the rotor current, stator current, rotor speed, torque value of squirrel cage IM connected to LSC i.e. output of VSC2. The Proposed topology is achieved the minimum THD compared with conventional controllers depicted in figure $12 \& 13$. The percent THD values of various loads are depicted in table 3 .

- Minimization of THD (Conventional controllers) $=7.03 \%$

- Minimization of THD (Proposed System Model $)=3.87 \%$

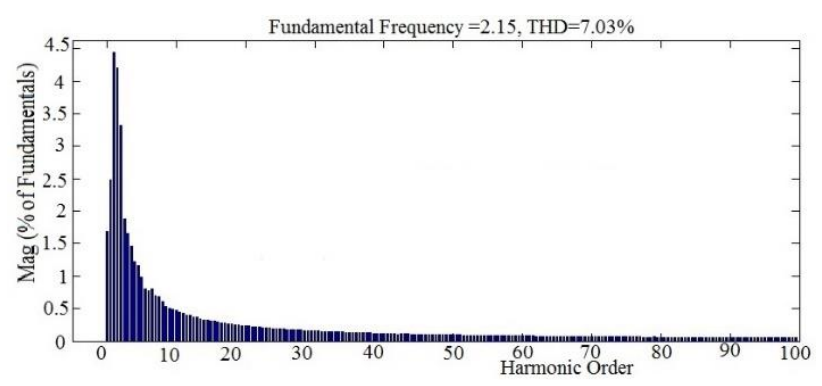

Figure.12 THD analysis through conventional controllers

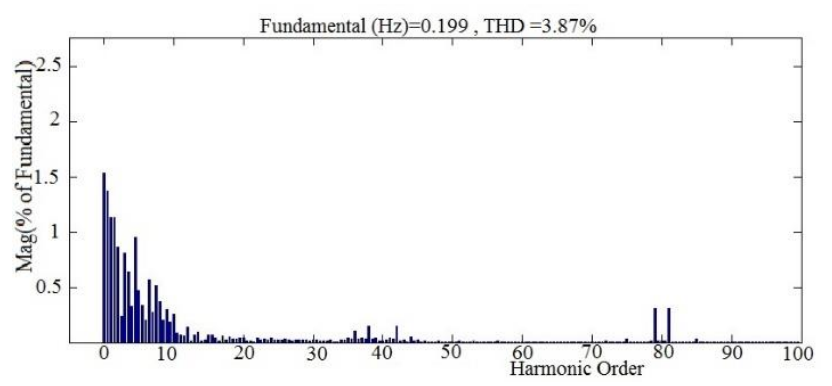

Figure.13 THD analysis through proposed model

\section{Conclusion}

In this paper, an integrated fuzzy and Adaline controller for PMSG -WECS for track maximum power from variable wind speed characteristics are studied. The designed controller has merits compared with conventional PI controllers to achieve the minimum THD. The methods use a fuzzy logic control to maintain the constant DC Voltage from VSC1 (MSC). The Adaline controller is designed by mathematical derivatives to achieve reactive power compensation and cancellation of harmonics generated by non linear loads. In addition to that LC filter are connected at VSC2 (LSC) to minimize the high frequency oscillations and eliminated the lower order harmonics created by converted ac power. From the simulated results, it has been verified that PMSG voltage remains constant feeding to three phase load using back to back voltage source converters. In Future work the Stationary and Time varying harmonics are estimated accurately at the point of PCC by using Non Linear Square (NLS) based FPGA Controller and eliminated by using suitable filter.

The specific conclusion from this proposed works are as follows:

1. A simple robust Adaline controller has been developed to extract the phase and quadrature templates at the PCC.

2. PMSG based WECS investigated under various non linear loads.

3. The result indicated that constant terminal voltage has been delivered at variable wind speed for maintaining constant DC link voltage.

4. The main focus of this work is to compensate the reactive power and to achieve the minimum value of THD under various load parameters.

\section{Notations \\ $R_{s,} R_{r} \quad$ Stator and Rotor Resistance \\ $L_{s}, L_{r} \quad$ Stator and Rotor Inductance \\ $L_{m} \quad$ Mutual Inductance \\ $w_{e} \quad$ Grid angular frequency \\ $w_{s}, w_{r} \quad$ Stator and rotor angular frequency \\ $\Psi_{q s}, \Psi_{q r} \quad$ Quadrature and Direct axis stator flux linkage vector \\ $\Psi_{d s,} \Psi_{d r} \quad$ Quadrature and Direct axis rotor flux linkage vector \\ $V_{d s}, V_{q s} \quad$ Direct \& Quadrature axis voltage components \\ $\sigma_{L S} \quad$ Stator leakage inductance \\ $K_{P}, K_{I} \quad$ Proportional and integral constant}



$P_{s}, Q_{s}$
Stator output active and reactive power
$V_{d r}, I_{d r}$
Direct axis voltage \& current
$V_{q r}, V_{d r}$
$V_{d c}$
Quadrature axis voltage \& current
$V_{a}, V_{b}, V_{c}$
DC link voltage
$U_{a q}, u_{b q}, u_{c q}$
Three phase voltage components
Quadrature phase templates

\begin{tabular}{|c|c|}
\hline \multicolumn{2}{|l|}{ Appendix } \\
\hline $\begin{array}{l}\text { PMSG } \\
\text { Specifications } \\
(1 \mathrm{MW})\end{array}$ & $\begin{array}{l}\text { Stator Resistance }=0.425 \Omega \\
\text { Armature Inductance }= \\
0.000835 \mathrm{H} \\
\text { Flux linkage estimated by } \\
\text { magnets }=0.433 \mathrm{~V} . \mathrm{s} \\
\text { Voltage Constant }=392 \mathrm{~V} \\
\text { Torque Constant }=3.2475 \mathrm{Nm} \\
\text { Rotor flux position when } \\
\text { theta }=0 \text { ( } 90 \text { degrees behind A } \\
\text { phase) } \\
\text { Wind Speed Set up to } 12 \\
\text { m/sec (Simulated in both fixed } \\
\text { and variable mode) }\end{array}$ \\
\hline $\begin{array}{l}\text { Machine Side } \\
\text { Converter (MSC)- } \\
\text { Voltage Source } \\
\text { Inverter (VSC1) }\end{array}$ & $\begin{array}{l}\text { VSC1 controls DC voltage } \\
\left(\mathrm{V}_{\mathrm{dc}}=480 \mathrm{~V}\right) \\
\text { PWM Frequency }= \\
33 * 50=1650 \mathrm{~Hz}\end{array}$ \\
\hline $\begin{array}{l}\text { Laod Side Converter } \\
\text { (LSC) - } \\
\text { Voltage Source } \\
\text { Inverter (VSC2) }\end{array}$ & $\begin{array}{l}\text { VSC2 controls Load side } \\
\text { voltage }\left(\mathrm{V}_{\mathrm{ac}}=360 \mathrm{~V}, 50 \mathrm{~Hz}\right) \\
\text { PWM Frequency }=1700 \mathrm{~Hz}\end{array}$ \\
\hline RL load-Load 1 & $20 \mathrm{KW}, 300 \mathrm{~V}_{\mathrm{rms}}, 50 \mathrm{~Hz}$ \\
\hline $\begin{array}{l}\text { Squirrel Cage IM - } \\
\text { Load } 2\end{array}$ & $\begin{array}{l}22 \mathrm{KW}, \mathrm{V}_{\mathrm{rms}}=2400 \\
\text { Stator Resistance \& Inductance } \\
=0.029 \Omega \& 0.05 \mathrm{mH} \\
\text { Stator Resistance \& Inductance } \\
=0.022 \Omega \& 0.05 \mathrm{mH}\end{array}$ \\
\hline
\end{tabular}

\section{References}

[1] S.Haier, "Grid Integration of wind Energy conversion systems", Hoboken, NJ, Wiley, 1998.

[2] S.N.Bandra, D.Kastha, and S.Banergy, "Wind Electrical Systems", New Delhi, India, Oxford university Press, 2004.

[3] L.L.Lai and T.F.Chan, "Distributed GenerationInduction and Permanent Magnet Generators", New York, Wiley, 2007.

[4] B. Singh and G.K. Kasal, "Voltage and frequency controller for a three phase four wire autonomous wind energy conversion systems", IEEE Trans. on Energy Conversion, Vol.23, no.2, pp.509-518, 2008.

[5] M. Singh and A. Chandra, "Application of adaptive network-based fuzzy inference system for sensorless control of PMSG-based wind turbine with nonlinear-load-compensation capabilities", IEEE Trans. Power Electron, Vol. 26, No.1, pp.165-175, 2011.

[6] M. Singh M, V. Khadikar, and A. Chandra, "Grid synchronisation with harmonics and reactive power compensation capability of a permanent magnet synchronous generator based variable speed wind energy conversion systems", IET Power Electronics, Vol.4, No.1, pp.122-130, 2011.

[7] A. Iqbal, S. Payami, M. Saleh, A. Anad, and R. K. Behra, "Analysis and control of a five-phase AC/DC/AC converter with active rectifier", In: Proc. of the 2012 22nd Australasian Universities Power Engineering Conference, pp. 1-6, 2012.

[8] V. Sheeja, P. Jayaprakash, B. Singh, and R. Uma, "Isolated wind energy conversion system for three-phase four wire loads employing Adaline based voltage-frequency controller", In: Proc. of the IECON 2012 - 38th Annual Conference on IEEE Industrial Electronics Society, pp. 10431048, 2012.

[9] L. Wang and D. N. Truong, "Dynamic Stability Improvement of Four Parallel-Operated PMSGBased Offshore Wind Turbine Generators Fed to a Power System Using a STATCOM", IEEE Transactions on Power Delivery, Vol. 28, No. 1, pp. 111-119, 2013.

[10] A.M. Gore and D. S. More, "Performance investigation of Shunt Active Power Filter with PI and fuzzy controllers", In: Proc. of the 2013 IEEE International Conference on Control Applications, pp. 1159-1164, 2013.

[11] T. H. Nguyen, D.-C. Lee, T. L. Van, J.-H. Kang, "Coordinated control of reactive power between STATCOMs and wind farms for PCC voltage regulation", J. Power Electron., Vol. 13, No. 5, pp. 909-918, 2013.

[12] L. Barote, C. Marinescu and M. N. Cirstea, "Control Structure for Single-Phase StandAlone Wind-Based Energy Sources", IEEE Transactions on Industrial Electronics, Vol. 60, No. 2, pp. 764-772, 2013.

[13] O. Alizadeh, A. Yazdani, “A Strategy for Real Power Control in a Direct-Drive PMSG-Based Wind Energy Conversion System", IEEE Transactions on Power Delivery, Vol.28, No.3, pp.1297-1305, 2013.

[14] L. Wang and D. N. Truong, "Stability Enhancement of a Power System With a PMSGBased and a DFIG-Based Offshore Wind Farm Using a SVC With an Adaptive-Network-Based Fuzzy Inference System", IEEE Transactions on Industrial Electronics, Vol. 60, No.7, pp. 27992807, 2013. 